Article

\title{
Paradoxes of Universalism: The Case of the Swiss Disability Insurance
}

\author{
Emilie Rosenstein * and Jean-Michel Bonvin \\ Department of Sociology, University of Geneva, 1211 Geneva, Switzerland; E-Mails: emilie.rosenstein@unige.ch (E.R.), \\ jean-michel.bonvin@unige.ch (J.-M.B.) \\ * Corresponding author
}

Submitted: 30 September 2019 | Accepted: 9 December 2019 | Published: 18 March 2020

\begin{abstract}
Social policies rely on specific expectations vis-a-vis their beneficiaries, who have to abide by certain eligibility criteria or behavioral standards to access the benefits or services provided. As such, they draw boundaries between the deserving and undeserving, which results in the following paradox: While social policies claim to be universal, they actually exclude potential beneficiaries by imposing on them the compliance with these eligibility criteria and behavioral standards. In other words, purportedly universal social policies may have exclusionary effects, in the form either of selectivity (street-level bureaucrats select what they perceive as legitimate beneficiaries) or of self-exclusion and non-take-up (people entitled do not claim benefits or services). Based on the case of the Swiss disability insurance, this article explores the extent of, and the reasons underlying, the paradoxes of universalism within active social policies. It relies on a mixed-methods research design, combining sequence analysis (showing the selectivity of active reforms regarding people's access to disability benefits) and in-depth interviews. The conclusion of this article suggests that not all forms of universalism are equally exposed to such paradoxes and proposes a hypothesis to be explored in further research: The more requiring and precise in terms of eligibility criteria and behavioral standards social policies and activation strategies are (hard universalism), the higher the risk that they lead to selective practices in contradiction with their universal ambition. By contrast, fuzzier eligibility or behavioral criteria (soft universalism), which allow for adjustment to individual circumstances, may lead to more genuinely universal and inclusive social policies.
\end{abstract}

\section{Keywords}

activation; capability; disability policies; selectivity; social policies; universalism

\section{Issue}

This article is part of the issue “'Universalism' or 'Universalisms' in Social Policies?” edited by Monica Budowski (University of Fribourg, Switzerland) and Daniel Künzler (University of Fribourg, Switzerland).

(C) 2020 by the authors; licensee Cogitatio (Lisbon, Portugal). This article is licensed under a Creative Commons Attribution 4.0 International License (CC BY).

\section{Introduction: What is at Stake with Universalism?}

Literature has abundantly shown that most social policies are characterised by a tension between universalism and selectivity. Rothstein considers them as ideal-types: On the one hand, universalism is characterized by a high degree of universal coverage, "i.e., benefits and services are intended to cover the entire population throughout the different stages of life, and on the basis of uniform rules... without the application of economic needstesting (or means-testing)" (Rothstein, 1998, pp. 19-20); on the other hand, selectivity refers to social policies that do not cover the entire citizenry, applying needs or means testing and delivering benefits according to what Rothstein calls "discretionary allocation," with a view to focusing on the "truly needy" (Rothstein, 1998). EspingAndersen's models of welfare (1990) show how countries combine both principles of universalism and selectivity in different ways. While the liberal model heavily relies on selectivity, i.e., on targeting and means-testing benefits, the social-democratic model, which characterises mainly Scandinavian welfare states, insists on the relevance of a universalistic approach providing generous cash benefits or in-kind services to all citizens or inhabitants of 
a country. Universalistic approaches have been put under pressure in the contemporary context, even among the countries pertaining to the social-democratic model (about such processes of "de-universalisation" see Goul Andersen, 2012; van Kersbergen \& Kraft, 2017). This results in a higher concern for containing social expenditure, generally coupled with the development of activation programmes conceived as the best solution to promote welfare recipients' return to the labour market and to reduce the caseload. It is then claimed that universalistic benefits tend to generate inactivity and poverty traps resulting in long-term exclusion or dependency on welfare. By contrast, selectivity is presented as a more efficient way to use public money as only those who really need benefits receive them, and in such a way that incentivises them to re-integrate the labour market and regain financial autonomy. This increased focus on targeting and selectivity is however not meant as the end of universalism in social policies, but rather as a new way to envisage the issue of universalism, which combines elements of selectivity or targeting with renewed conceptions of universalism based on notions such as "targeting within universalism" (Skocpol, 1991), "quasiuniversalism" (Leisering, 2009), "conditional universalism" (Ferrera, 1998), etc. In this article, we want to examine these new configurations and their inclusionary or exclusionary effects in the field of disability policies.

We will show what impact such configurations have on the access to disability policies (be it cash benefits or in-kind services). We aim at analysing whether, how, and why "conditional universalism" based on activation requirements produces paradoxical impacts on beneficiaries. Indeed, activation policies rely on specific expectations vis-a-vis their beneficiaries, who have to abide by certain eligibility criteria or behavioural standards to access the benefits or services provided. As a result, purportedly universal social policies may have exclusionary effects. Our research shows that, in practice, not all eligible people are benefitting from such activation measures, either because of selectivity-streetlevel bureaucrats select those they perceive as legitimate beneficiaries-or of self-exclusion and non-takeup-people entitled do not claim benefits or services (Rosenstein, 2018). It is precisely this paradox, of a programme designed to encompass all recipients and practically excluding some of them, that will be the centre of our attention.

This article explores the extent of, and the reasons underlying, this paradox resulting from a universalistic approach to activation and its selective implementation. Our focus is not on the fundamental gap between political discourses and their actual implementation that may result in forms of selectivity-this has been abundantly documented since Michael Lipsky's (1980) seminal work on the discretionary power of street-level bureaucrats. Rather, our ambition is to understand why efforts to enlarge access to active programmes and make activation a universal path for welfare recipients, result in forms of selectivity that exclude many of them from activation tracks. To address this issue, we investigate the case of the Swiss disability insurance (DI), which has recently undergone a series of active reforms with a view to extending access to activation programmes and support disabled people in entering or returning to the labour market.

Our analyses rely on a mixed-methods research design. Section 2 provides an overview of the policy context of Swiss disability policies and its recent evolution. Section 3 presents the data and methods used. Section 4 is articulated in three subsections: Section 4.1 presents the overall impact of activation on DI claimants' trajectories, revealing the tensions between purposed universalism and actual selectivity; Section 4.2 focuses on the impact of age on access to disability benefits; and Section 4.3 highlights inequalities according to the type of impairment. Section 5 concludes and draws recommendations for closing or rather shortening the gap between discourses of universalism and practices of selectivity. It suggests that the capability approach may well represent the foundation for a more respectful and effective universalism.

\section{DI and its Active Reforms: A Brief Contextualisation}

DI (Assurance-invalidité in French, or Invalidenversicherung in German) is a central institution of the Swiss welfare system. Its mission is twofold: On the one hand, to prevent, reduce, or eliminate disability, this is the rehabilitation or activation part; on the other hand, to compensate citizens' loss of income resulting from disability, this is the financial compensation part. To do so, DI provides two kinds of benefits that are mutually exclusive: vocational rehabilitation measures (accompanied by daily allowances) and long-term disability pensions (that can be full or partial pensions, depending on claimants' loss of income). Since the creation of DI in 1960, its motto has always been "Rehabilitation before pension," i.e., pensions are meant to be a last resort solution for those people who cannot be rehabilitated. However, the number of pension recipients steadily increased over the years (OFAS, 2018), especially since the early nineties (+89\% between 1990 and 2005), thus confronting the DI to major financial difficulties. To face this situation and reduce the number of pensions, a series of legal reforms were designed that had deep-seated consequences on DI implementation at the local level. Inspired by the principles of activation and following the $\operatorname{OECD}(2003,2006)$ recommendations, the Federal Law on DI was amended three times in a row, over a very short period (in 2004, 2008, and 2012) with a view to increasing the outflow. The cornerstone of this active turn of DI was undoubtedly its 5 th revision.

Implemented in 2008, the aim of the 5th revision of DI was to reduce by $20 \%$ the number of new pensions granted every year. To reach this goal, the premise was to invest massively in vocational rehabilitation pro- 
grammes in order to make them more accessible and efficient. This implied a four-fold activation strategy. First, accelerate the procedures and introduce early detection and intervention programmes in order to preserve recipients' working capacity and optimise their chances to return (or remain) on the labour market. Second, develop the catalogue of vocational rehabilitation programmes to make it more congruent with disabled people's needs, including job placement programmes. Third, hire about 300 additional case managers to follow DI beneficiaries at the local level. And, fourth, reinforce recipients' individual responsibility, including their duty to collaborate and commit themselves actively in rehabilitation measures. This implied the adoption of a new sanction regime, also accompanied by new tools to fight against fraud. All these evolutions pointed to the ambition of effectively implementing universalistic activation to all people with a residual working capacity that could be used on the competitive labour market. These reforms were thus faithful to the initial motto "Rehabilitation before pension," claiming to fully implement it in the actual DI practices. It is precisely the effectiveness of this claim that we investigate in this article, trying to identify successes and failures and the reasons underlying them.

\section{Data and Methods}

The study on which this article is based mobilised a mixed-methods research design, including:

1. A documentary analysis (based on legal documents, public reports, and statistics);

2. Semi-directed interviews with DI local actors (managers, case managers, doctors, psychologists, etc; $\mathrm{N}=22$ );

3. In-depth biographical interviews with people who claimed for DI benefits $(N=23)$;

4. Sequence analysis $(N=1500)$, applied to a sample of people who applied to the Office of DI in the canton of Vaud (the biggest DI office in the Frenchspeaking part of Switzerland).

The complementarity of these methods and the triangulation of data have been conceived as follows: First, we carried out the documentary analysis in order to understand the legal context in which DI operates, and to identify the major social and economic issues faced by DI over the last decades. This first step allowed us to grasp the meaning of DI reforms, the aims, and the means of activation in this specific welfare context. Second, we completed the sequence analyses, in order to measure the longitudinal impact of active reforms on the administrative trajectory of three cohorts of DI claimants. On this basis, we identified specific trends that guided our questioning through qualitative interviews. Third, we proceeded to semi-directed interviews with DI local actors in order to grasp the way they interpret and implement DI reforms. Finally, we sampled DI claimants belonging to the three cohorts analysed statistically in order to complete in-depth biographical interviews. The sampling was based on the results of the sequence analyses, identifying three groups according to their administrative trajectories: people who were entitled to a vocational rehabilitation measure (the activated group), people who received a DI pension (the so-called "passive" group) and people who were considered as not eligible to DI benefits (the refusal group). In order to carry out in-depth biographical interviews with a variety of people belonging to each of these three groups, the sampling was made taking into account three variables: age, gender, and type of impairment of respondents.

This article relies mainly on the quantitative analyses, complemented by some references to the documentary analysis and the qualitative interviews; therefore, we present our quantitative methodology in some more detail. We used sequence analysis to provide a longitudinal view on the effect of DI reforms on claimants' trajectories. To do so, we used administrative data provided by the local disability office of the canton of Vaud. These include socio-demographic data such as year of birth, sex, health impairment, together with information about the administrative trajectory of beneficiaries (for instance whether and when their application was accepted, what type of benefits they received, etc.). We created three representative sub-samples of 500 individuals, randomly selected according to the year of their first application for DI benefits (respectively in 2000, 2004, and 2008). These years were chosen in order to capture the impact of activation reforms presented above. Then, we reconstructed their administrative trajectory over the 48 months following their application. In the figures presented below, the horizontal axis corresponds to the time passing by, with $t+0$ designating the month of application. The vertical axis indicates the relative part of each state composing our alphabet, i.e., each administrative state that DI claimants may have encountered after their application. This includes states within DI schemes (like the period of assessment of their application or the granting of DI benefits) but also states designating the way they left DI (for instance, after a job placement or a refusal of their claim for benefits). The administrative data includes a high multiplicity of such states, we thus coded them into 10 categories. To highlight the effects of activation on claimants' trajectories, this article focuses on the comparison of the cohorts who claimed for benefits in 2000 (before DI active reforms) and 2008 (after active reforms).

We attributed a specific colour to each of the 10 states that may occur along the claimants' administrative trajectory (see legend of Figures 1, 2, and 3). Assessment (in red) corresponds to the administrative state during which claimants' eligibility to DI benefits is examined, both in legal and medical terms. Partial pension (in orange) and full pension (in yellow) show the proportion of claimants who are granted a DI pension, generally on the long-term. So-called "helplessness allowances" (in dark green) are granted to pensioners who need specific care 
services due to the severity of their disability. Vocational rehabilitation (in light green) includes all training programmes funded by DI in order to improve beneficiaries' earning capacity. This includes mainly certified training programmes. Placement (in blue-grey) gathers the job placement programmes introduced by DI active reforms. Refusal (in light blue) designates the part of claimants assessed as not eligible for benefits. Temporary exit (in dark blue-grey) is an uncommon state, referring to the situation of people who temporary left the DI, after a shortterm vocational rehabilitation measure and before a second application. Unlike temporary exit, permanent exit (in dark blue) corresponds to the case when beneficiaries definitely left the $\mathrm{DI}$ after the end of a vocational rehabilitation programme. This state also includes the very limited number of cases of people who exited the DI after their pension was suppressed. Retirement (in mauve) entails the situation of people who left DI because they entered the retirement pension scheme. Finally, death (in purple) shows the part of claimants whose follow-up by DI was suppressed because they passed away.

\section{Results}

\subsection{Activation between Universalistic Discourses and Selective Practices}

The first paradox we identified relates to the gap between the formal ambition of activating every beneficiary with a remaining earning capacity, as it appears in political discourses and policy designs (including legal texts and institutional documents), and its actual implementation and translation into welfare claimants' trajectories. The question at stake here is to establish a precise diagnosis about the extent to which activation programmes are inclusive or exclusive and activation can be considered as a universal and inclusive path.

When the main active reform of DI was introduced in 2008 , the objective was to improve the access to vocational rehabilitation programmes in order to increase the outflow. This implies that, for each person who claims for DI benefits, the opportunity of a vocational rehabilitation must be thoroughly examined before considering his or her eligibility to a pension. As proclaimed by the Swiss Federal Council in its message supporting DI 5th revision:

In the future, it will be more difficult to access pensions for insured people with health difficulties that impact their earning capacity. They will be entitled to a DI pension if and only if their earning capacity, in all likelihood, cannot be restored, maintained, or improved through rehabilitation measures that could be reasonably required. Besides, specific attention will be paid to what activities can still be, from an objective viewpoint, reasonably required from them, despite their health difficulties....Such strengthening of the conditions for the granting of pensions is compensated by the reinforcement of rehabilitation pro- grammes. (Swiss Federal Council, 2005, p. 4287, authors' translation)

Besides, the duty of claimants to collaborate and commit themselves actively in rehabilitation measures has been strongly emphasised:

In the future, insured people will play a leading role in their own rehabilitation. By collaborating actively with the DI and by complying with their duty to cooperate, they will show that they truly aim at their reinsertion in active life with the support of competent people and that they take their responsibilities accordingly. They thus also fulfil their obligation to reduce the damage or harm that caused their disability, thus doing a great service to themselves and society. When insured people do not display the expected commitment and do not fulfil their duty to collaborate, they will henceforth be sanctioned more quickly and more directly, in the form of a benefit reduction or refusal. (Swiss Federal Council, 2005, pp. 4281-4282, authors' translation)

Thus, the willingness to push DI beneficiaries into activation is very clearly stated, insisting that activation is the only practicable path for people who have a residual working capacity. As summarised by an interviewed DI employee: "It is like a noose around claimants, to whom we say, 'You have the choice between being rehabilitated and being rehabilitated."' In short, it is claimed that there is no way out of activation, which is conceived as a panacea for all beneficiaries with a residual working capacity. For street-level bureaucrats too, activation through vocational rehabilitation programmes is presented as the most appropriate solution, which ought to be tried whenever there seems to be an even limited chance for success. Granting activation programmes is highly valued by the tools and indicators used to monitor their activity; conversely, if activation fails, this is not sanctioned, i.e., if activated people get a disability pension in the end because rehabilitation attempts proved to be ineffective, this is not considered as a bad performance.

However, if we look at Figure 1, comparing the administrative trajectories of people who claim for disability benefits before (2000) and after (2008) the DI active turn, vocational rehabilitation measures (in light green) are far from being a universal and inclusive path. Indeed, if we compare the proportion of people involved in a rehabilitation programme one year after they applied for DI benefits, we see that they represented $3 \%$ of the 2000 sample, against $8 \%$ of the 2008 sample. This shows that, even if the access to rehabilitation is higher for the most recent cohort, it remains highly selective, in spite of the introduction of early intervention tools and the acceleration of DI assessment procedures (in red). Taking as an indicator the situation at $\mathrm{t}+12$ (one year after they applied for DI benefits), we see that $75 \%$ of the 2000 sam- 


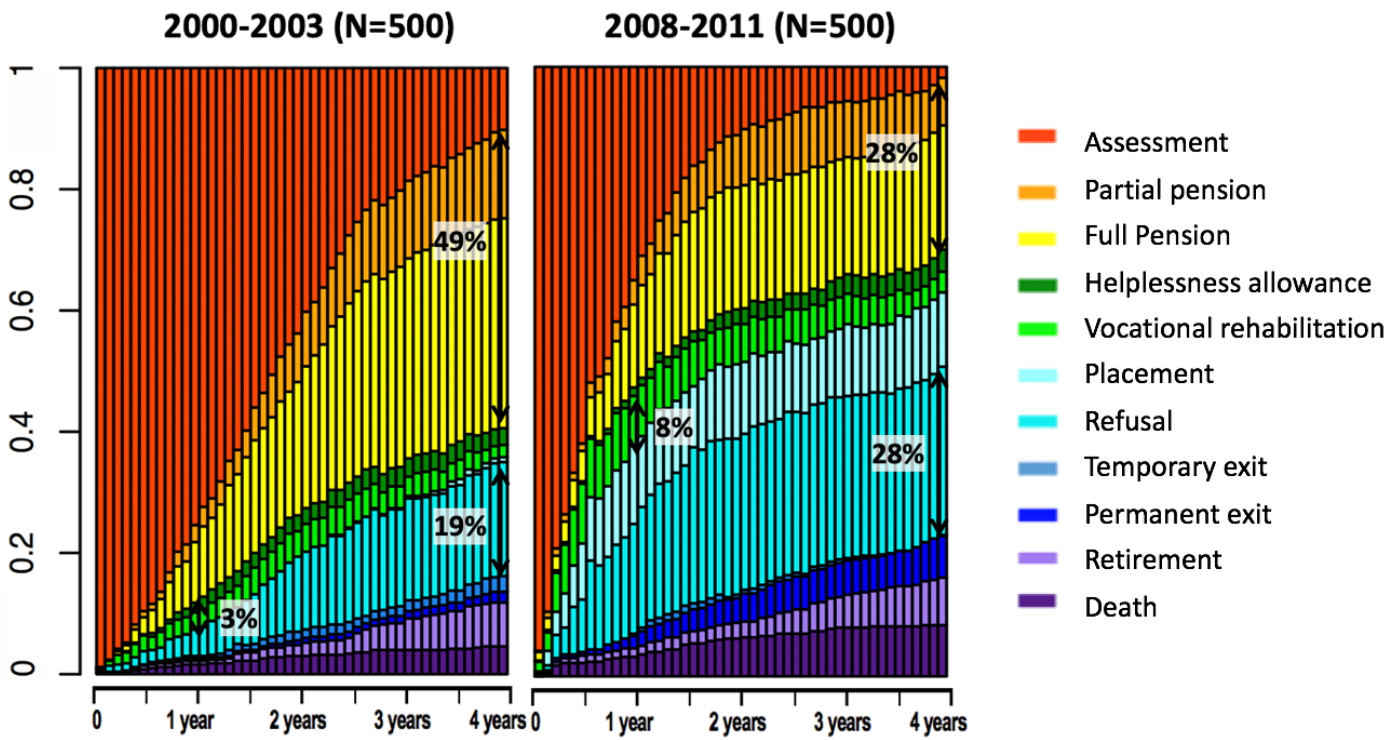

Figure 1. Comparison of two cohorts of DI claimants (2000 and 2008). Source: Rosenstein (2018; computed on the basis of administrative data provided by the DI Office of the canton of Vaud).

ple were still waiting for DI decision, against 35\% among the 2008 cohort. The speed at which files are processed has been considerably increased but this does not, as yet, result in a much higher proportion of activated people.

Moreover, our sequence analyses show that active reforms result in a decrease in the number of pensions delivered by DI. If we compare the situation at $t+48$, we see that while almost one person out of two (49\%) used to benefit from a DI pension four years after their application in 2000 (be it a partial pension-in orange, or a full pension-in yellow), only $28 \%$ of the 2008 cohort was granted a pension. This massive reduction in the number of pensions delivered by DI does not coincide with an equivalent increase of the number of activated people. Rather, it is explained by the rise in the number of refusals (in light blue), i.e., the people who were considered as not eligible to DI benefits. Four years after their application, $19 \%$ of the 2000 cohort left DI after a refusal, while $28 \%$ of the 2008 cohort were in the same situation. Thus, paradoxically, the objective of universal activation, i.e., of including all people with a residual working capacity into rehabilitation programmes, resulted in excluding them altogether from $\mathrm{DI}$ benefits more than in increasing the rate of activation within DI.

This first set of analyses provides a good illustration of the paradox of activation and its claim to universalism. While vocational rehabilitation is officially presented as the only path for all people with a residual working capacity (we could even speak of a universal duty to activate in their case), our results show that it remains highly selective. Only a few people seem to fulfil the requirements to enter and complete a vocational rehabilitation programme. This questions the effective accessibility of rehabilitation programmes for disabled people with a residual earning capacity. Indeed, we observe a clear gap between the political will to enlarge access to activation and its actual and limited implementation, in spite of a clear speed up in file processing. However, it should be mentioned that this very limited increase in the access to vocational rehabilitation programmes may in part result from the fact that the analysis focuses on the cohort of 2008 , i.e., the very year when the 5 th revision was adopted. We could indeed formulate the hypothesis that the full implementation of active reforms may take more time and thus the impact may be more significant among more recent cohorts.

Our results also show a disconnection between the limited rise in the number of people involved in vocational rehabilitation and the significant reduction in the number of pensions delivered. This seems to invalidate the assumption underlying the DI reforms that there is a causal effect between investing in vocational rehabilitation programmes and reducing the number of pensions delivered. Rather, it appears that activation reforms have been more effective in reducing the access to socalled "passive" measures than in promoting an active support to DI claimants. All in all, this tends to suggest that the conception of universalistic activation underlying the Swiss DI reforms has a twofold exclusionary effect: It proves largely unable to include people into rehabilitation tracks, while it is much more efficient in excluding disabled people from DI benefits in general. This conclusion does not equally apply to all categories of recipients, however. It thus needs to be contrasted along the age and the type of impairment of DI claimants.

\subsection{Age as a Factor of Exclusion}

As illustrated in Figure 2, we observe important inequalities between youngsters and other generations in terms of accessing vocational rehabilitation programmes. Indeed, in both the 2000 and the 2008 cohorts, the 


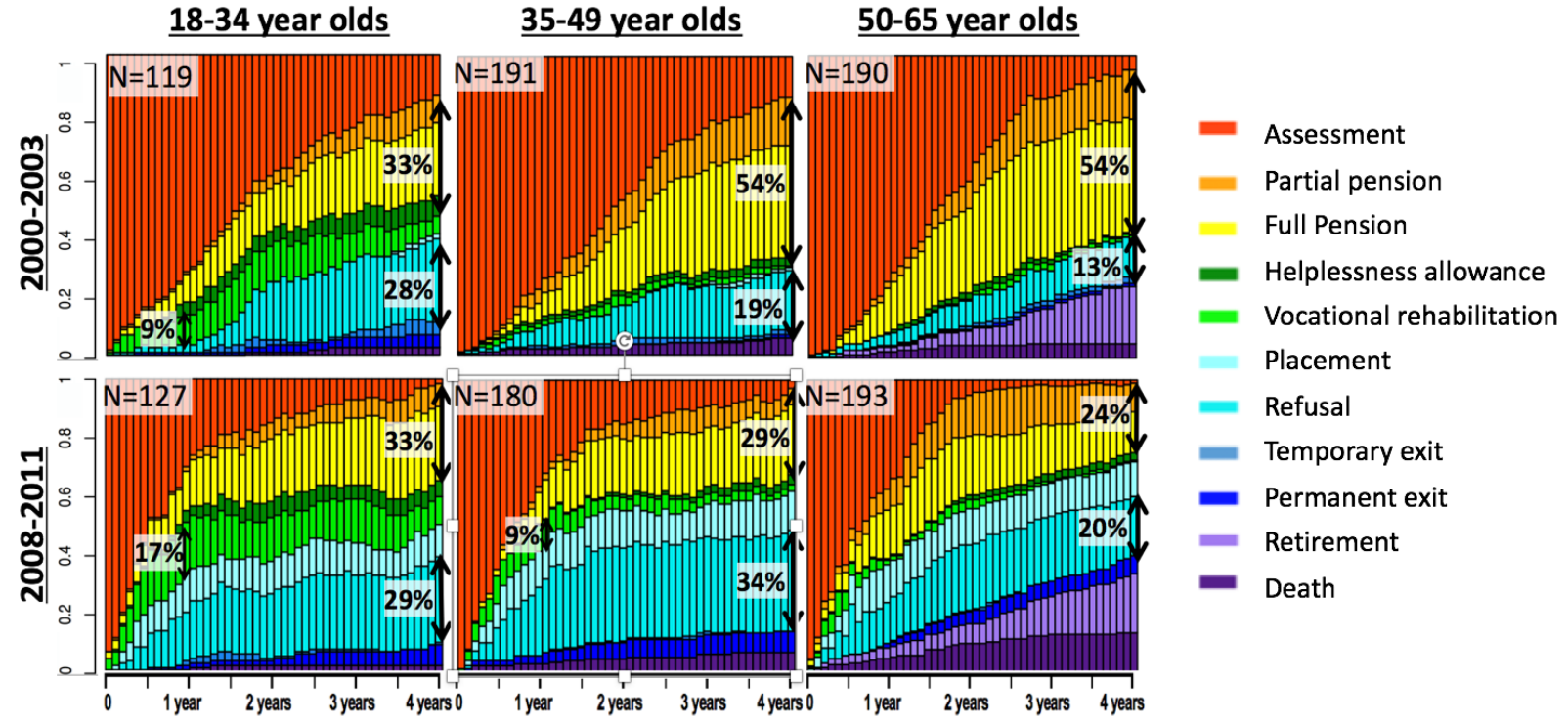

Figure 2. Comparison of two cohorts of DI claimants, according to age. Source: Rosenstein (2018; computed on the basis of administrative data provided by the DI Office of the canton of Vaud).

vast majority of vocational rehabilitation programmes (in light green) were granted to people belonging to the 18-34 age group. If we compare the situation at $t+12$ (one year after the application), in the 2000 cohort (upper half of Figure 2), 9\% of the 18-34 year old were involved in active measures, against less than $2 \%$ among the 35-49 year old and none of the 50-65 year old. In the 2008 cohort, the access to vocational rehabilitation programmes progressed, but still in an uneven way: At $t+12,17 \%$ of the youngsters followed a vocational rehabilitation programme, against $9 \%$ among the middle age group, and less than $2 \%$ among the seniors. Thus, access to active programmes varies along the recipients' age, which confirms that activation is not a universal path, rather it tends to follow unequal patterns according to age categories.

Besides, our results reveal another limitation of DI reforms. While these were particularly aimed to tackle the increasing number of young pensioners, our analyses show that their rate has not decreased. The share of 18-35-year-old receiving pensions (full and partial) remained the same for both cohorts (33\%, 4 years after their application). By contrast, for the 35-49 and 50-65 age groups, the impact has been very tangible and is reflected in a marked increase in benefit refusals $(+79 \%$ among 35-49-year old, and $+54 \%$ among 50-65-year old). Unlike the situation of young people, access to pensions for the older age groups has been significantly reduced, without any proportional progress in their access to vocational rehabilitation measures. For example, $9 \%$ of the 35-49-year-old belonging to the 2008 cohort were involved in active measures one year after their application (against less than 2\% among the cohort of 2000).

These inequalities ought to be interpreted in relation to the selectivity operated by the labour market itself, especially regarding middle aged and senior work- ers. Interviews with both DI local agents and DI claimants underline the obstacles faced by middle and old age disabled people when they are looking for a job. As this recipient puts it:

Even the counsellor of the unemployment insurance told me that with my age and my health issues, I won't find a job. So what am I supposed to do? I am too young to be retired and too old to find a job.

Taking into account the selectivity of the labour market, DI local agents themselves operate their own selection among beneficiaries. As this DI employee confirms:

Maybe we devote less energy to certain beneficiaries. Of course, we have a certain deontology and we have to treat everyone in the same way. But we must also deliver results, so we have to focus on people who have the potential to succeed. We devote a little more energy on these cases, also because they will have more solutions within their reach.

This example illustrates what Merton (1968) calls "Matthew effects," i.e., a reinforcement of the advantages and resources provided to the most favoured individuals or groups, while the situation of the most vulnerable ones gets worse. In the present case, Matthew effects may lead to the exclusion of middle or old-age claimants from active tracks. This takes place especially when activation is conceived as a social investment that needs to deliver high returns (Bonoli, Cantillon, \& van Lancker, 2017). This points out a second paradox or limitation of a universalistic approach to activation. By focusing on the necessity to adapt claimants to employers' requirements, activation produces forms of selectivity that tend to reproduce patterns of inequalities on the labour 
market, supporting the ones that appear as more "includable" or "adaptable" and excluding the others from activation tracks.

\subsection{Health Impairments and the Limits of Universalism}

Important differences can be observed between the trajectories of people according to their health status. Figure 3 compares the trajectory of people who applied for DI benefits in 2000 and 2008, according to the type of impairment they were confronted to. We grouped them in three categories: people with a physical impairment; people with a psychical impairment-this category includes all cases cumulating both physical and psychical impairments; and people for whom DI agents concluded that there was no impairment. It should be noted that our definition of psychical impairment relies on the official classification of impairments used by DI (including psychoses, neuroses, and personality disorders). This classification is based on a medical approach to impairment that does not coincide with the biopsychosocial model used, for example, by the World Health Organization in its International Classification of Functioning, Disability and Health. The proportion of people with a psychical impairment among DI pension recipients increased significantly during last decades, becoming the leading cause of disability in Switzerland. As such, it has been specifically targeted by DI and its recent reforms.

Within the cohort of 2000 (upper half of Figure 3), vocational rehabilitation measures (in light green) were mainly allocated to people with a physical limitation (7\% of them were involved in a rehabilitation programme two years after their application, against less than $2 \%$ among people with a psychical impairment). But the 2008 cohort reveals that the balance has changed with the implementation of the DI active reforms. Among this cohort, people with a psychical impairment benefitted more often of vocational rehabilitation programmes than people with a physical disability. Thus, one year after their application, $16 \%$ of people with a psychical impairment were involved in an active programme, against $9 \%$ among people suffering from a physical limitation. This change mainly results from the introduction in 2008 of specific rehabilitation measures devoted to people with psychical impairments, which were conceived as a solution to curb their increasing number among people receiving a disability pension.

What is even more revealing is to compare the three categories against the proportion of people exiting from disability schemes. Indeed, when looking at the proportion of people leaving the DI after a job placement measure (in blue-grey) or in case of a definitive exit (in dark blue) in 2008, we see that they are more frequent among people with a physical impairment than among people with a psychical impairment. For example, four years after their application in 2008, $15 \%$ of the people with a physical condition were involved in a job placement programme, against $9 \%$ among people with a psychical impairment. Such programmes are the closest to the labour market and the rate of participation into these programmes can thus be used as a yardstick to assess the efficiency of activation programmes. Hence, these results show that activation measures are significantly less efficient to promote the inclusion of people with a psychical impairment on the labour market. This seems to suggest that, even with a considerable investment and commitment of DI and of its recipients towards activation, the probability of exiting DI schemes and returning to the labour market remains unequal and less accessible to people with a psychical impairment.

This points to a third paradox of universalistic approaches to activation, i.e., that activation is not the

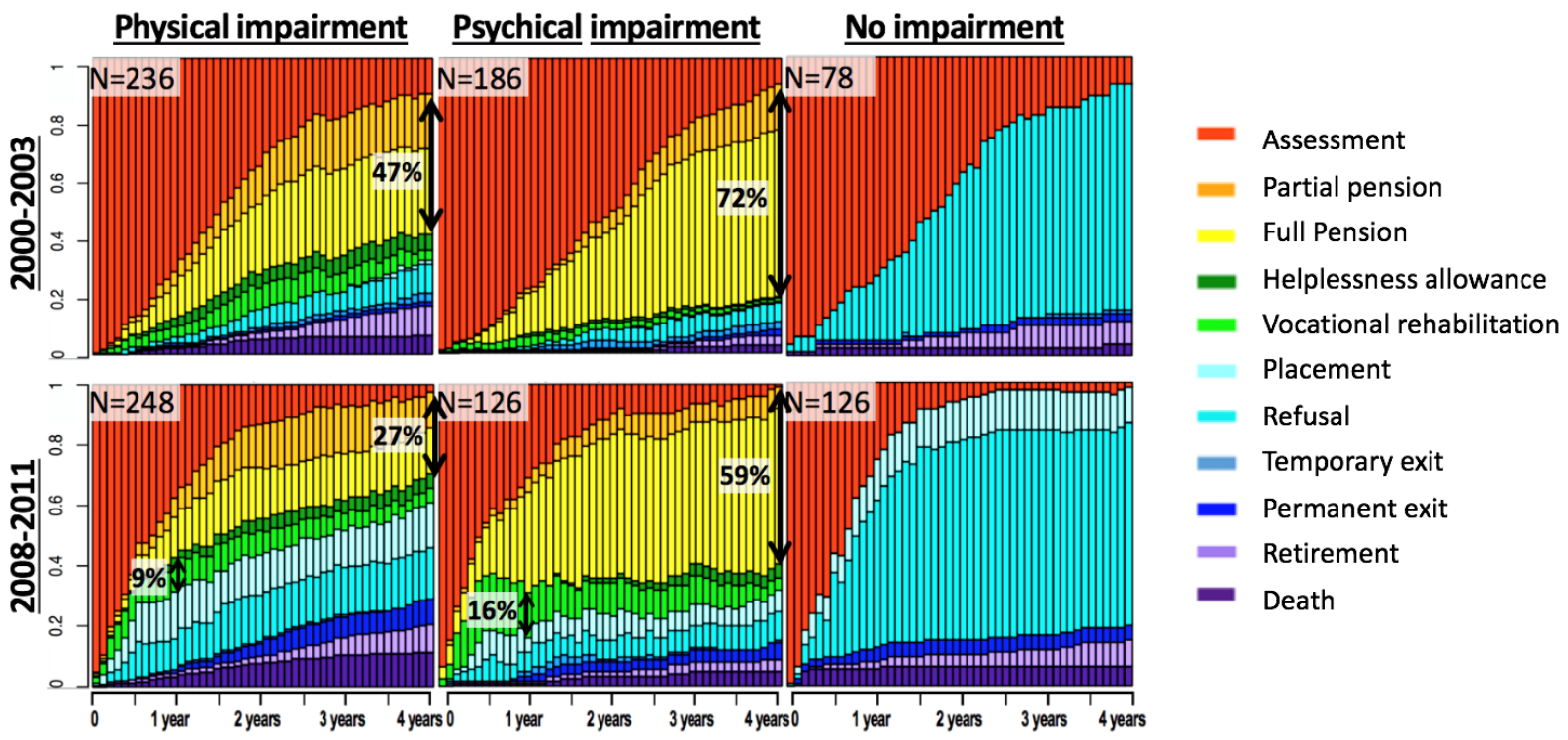

Figure 3. Comparison of two cohorts of DI claimants, according to the type of impairment. Source: Rosenstein (2018; computed on the basis of administrative data provided by the DI Office of the canton of Vaud). 
panacea to promote inclusion. On the contrary, our results show that activation by itself does not constitute an appropriate or sufficient remedy to promote inclusion for all. The case of people with psychical impairments illustrates this paradox. For them, there is a risk that the obstacles they face in vocational rehabilitation or job placement programmes that are not appropriate or tailor-made enough regarding their specific needs, are interpreted as signals of their incapacity to be included in the labour market. In such cases, people with psychical impairments are left with no other forms of support than pensions. This is precisely what happened to this beneficiary:

I found a job, but I broke down. I resisted for about a month and then, one morning, I collapsed. I got up to a point where I did not sleep anymore. So I said to the DI counsellor 'Listen, I cannot make it.' It was a fixed-term employment, partly subsidised by DI, but it was full-time and I broke down.... had everything in my hands to succeed. In addition, with a good salary. I asked the director to lower my activity rate to $50 \%$ but she said to me, 'I cannot, I need someone $100 \%$.' So immediately after that, I asked for a $50 \%$ DI pension.

This example illustrates how the notion of universalism purported by the reformed DI may paradoxically result in polarising welfare trajectories of inclusion/exclusion. This is confirmed by Figure 3, revealing a differential access to disability pensions according to the type of impairment. In both the 2000 and the 2008 cohorts, access to pension is uneven, but the evolution of the situation provides interesting insights. Indeed, while in the 2000 cohort, $47 \%$ people with a physical limitation were receiving a disability pension four years after their application, they were only $27 \%$ in the same situation in the 2008 cohort. In the same way, $72 \%$ among people with a psychical impairment were receiving a disability pension four years after their application in the 2000 cohort, against 59\% in the 2008 cohort. We thus observe a reduction in the proportion of pension recipients for both categories on the one hand, and a widening gap between the two categories on the other hand. This shows the differential ability of the reformed DI to activate recipients: while people with physical problems could be activated to a significant extent (thus reducing the caseload from $47 \%$ to $27 \%$ ), such was not the case for people with a psychical impairment (from $72 \%$ to $59 \%$ ), showing a lower capacity to provide inclusion through activation for this latter category.

Finally, Figure 3 also reveals a considerable decrease in the proportion of people with psychical impairment from 2000 to 2008 ( $N=126$ or $25 \%$ of the overall 2008 sample, compared to $\mathrm{N}=186$ or $37 \%$ of the 2000 sample). At the same time, we see that the proportion of individuals for whom DI employees concluded that they had no impairment (third column of Figure 3 ) increased from $16 \%$ of the 2000 sample $(N=78)$ to $25 \%$ of the 2008 sample $(N=126)$. This suggests that the introduction of a universalistic approach to activation in 2008 paradoxically resulted in an increase of the number of refusals to grant DI benefits and services, i.e., in a higher selectivity towards DI claimants. This is due, to a large extent, to the tightening of eligibility criteria discussed in the previous sections. Furthermore, we see that this selectivity does not operate randomly, but concerns much more significantly people with a psychical impairment, as is shown by the considerable decrease of their proportion in the 2008 cohort. Thus, rather than promoting inclusion for all, activation exacerbates inequalities at the expense of people with psychical impairments. As a matter of fact, it appears that the active turn of DI polarised the probability to access DI benefits and services or to exit the DI track on the long run, according to the type of impairment. This in turn confirms that activation is not a universal path.

\section{Conclusion}

Throughout this article, we tried to understand how and why purportedly universal social policies may have exclusionary effects. Based on a mixed-methods research design, applied to the case of the Swiss DI, we identified three paradoxical effects of a universalistic approach to activation on the inclusion/exclusion of vulnerable people. The first paradox relates to the gap between the official ambition to promote activation as a universal path for all people with a residual earning capacity, as it appears in political discourses and policy designs, and its actual implementation at the local level. Our analyses have shown that even if the access to activation programmes has slightly improved, they are by no means universally accessible insofar as only a few claimants seem to fulfil the requirements of activation. Besides, our results also pointed out that the active turn of DI resulted in a massive reduction of the access to pensions. As such, the universalistic approach to activation, rather than promoting inclusion by broadening the access to vocational rehabilitation programmes, seems to be more successful in denying access to so-called passive measures such as disability pensions. The second paradox points to the fact that despite its universal ambition, individuals are not on an equal footing in front of activation. Our analyses have shown for instance that vocational rehabilitation programmes are barely accessible for people over 35 years old. These inequalities have to be interpreted in relation to the selectivity of the labour market that makes people more or less likely to be employed, notably according to their age. The risk is thus that DI local agents exclude the least employable beneficiaries from activation programmes in order to focus on those who seem to demonstrate the highest probability to be included on the labour market. As such, universalistic approaches to activation are subjected to Matthew effects. Finally, the third paradox concerns the fact that universalistic ap- 
proaches to activation do not seem to be equally successful for all beneficiaries. Comparing the trajectories of DI claimants according to their health status displays important inequalities in terms of inclusion in the labour market. As a matter of fact, people with a psychical impairment are less likely to enter the labour market, even if important efforts are deployed to make vocational rehabilitation programmes more accessible to them.

All three paradoxes provide insights into the processes underlying the gap between a universalistic approach to activation and its selective outcomes. Additionally, a fourth paradox should be considered (even if our quantitative analyses do not allow measuring precisely its impact). It refers to the issue of non-take-up and the situation of people who, for many different reasons, do not claim welfare benefits they are entitled to (see, for example, van Oorschot, 1991, 1995). As we have shown elsewhere (Rosenstein, 2018), activation may reinforce the non-take-up of welfare benefits or services by making people reluctant to endorse the duties and behavioural requirements that have been strengthened by active reforms. In-depth biographical interviews carried out with DI claimants reveal the negative impact of active reforms on their perceived eligibility and on their beliefs and feelings associated to DI, which have been shown to be prerequisites to claiming for benefits (Kerr, 1982). More specifically, activation tends to erode people's sense of entitlement (Hobson, 2014) and produces non-take-up or delayed take-up, which is paradoxical regarding the objective of early intervention promoted by DI reforms. As such, beside the forms of selectivity presented in Section 4 above, a universalistic approach to activation may also result in forms of self-selection and non-take-up.

These findings also apply to other policy fields and contexts, beyond Switzerland and the case of disability policies, and may shed light upon why the universal ambition of activation policies often results in practices of selectivity and exclusion. Further research should examine whether all forms of universalism are equally exposed to such paradoxes. We could for instance differentiate between two ideal-typical versions of universalism. The first one sets high and precise standards in terms of eligibility criteria and behavioural requirements and focuses on individual responsibility and supply-side policies rather than social responsibility and demand-side policies. In this case, universalistic approaches to activation impose high burdens of individuals who have to adapt to institutional requirements and may be excluded altogether from activation programmes if they do not meet these expectations. We suggest labelling this first ideal-type "hard universalism." The second one relies on less precise and less requiring eligibility or behavioural criteria, leaving more space to take into account recipients' abilities and aspirations and to develop tailor-made programmes. It advocates a more balanced combination of individual and social responsibility, and of supplyand demand-side policies when it comes to including people in the labour market. This second version could be more inclusive as it pays more attention to people's actual situation and aspirations. We propose calling this second ideal-type "soft universalism." Our contention is that hard universalism may have significant exclusionary effects for all those who cannot fulfil its requirements, either due to selectivity by welfare employees assessing them as unfit for activation or via self-selection (or rather self-exclusion) due to a perceived inability to meet the official expectations. By contrast, soft universalism, where requirements may be to a larger extent adjusted according to people's circumstances and aspirations, may lead to more inclusivity and effective universalism, although it would not eliminate of course all forms of selectivity. Actual programmes are situated in-between these idealtypical situations. We suggest here that one key explanation of the paradoxes of activation within the Swiss DI could well lie in its tendency to privilege a hard version of universalism. Further research would be needed to explore this hypothesis in more depth, for instance by investigating the outcomes of programmes that give more space to soft universalism.

\section{Acknowledgments}

We would like to thank Felix Bühlmann for his essential contribution to the sequence analyses presented in this article. We are also very grateful to the editors of this thematic issue, as well as three anonymous reviewers for their useful and constructive comments. This publication also benefitted from the support of the Swiss National Centre of Competence in Research (NCCR) "LIVES-Overcoming Vulnerability: Life Course Perspectives," which is financed by the Swiss National Science Foundation (No. 51NF40-160590). The authors are grateful to the Swiss National Science Foundation for its financial assistance.

\section{Conflict of Interests}

The authors declare no conflict of interests.

\section{References}

Bonoli, G., Cantillon, B., \& van Lancker, W. (2017). Social investment and the Matthew effect: Limits to a strategy. In A. Hemerijck (Ed.), The uses of social investment (pp. 66-76). Oxford: Oxford University Press.

Esping-Andersen, G. (1990). The three worlds of welfare capitalism. Cambridge: Polity Press.

Ferrera, M. (1998). The four 'social Europes': Between universalism and selectivity. In M. Rhodes \& Y. Mény (Eds.), The future of European welfare: $A$ new social contract? (pp. 81-96). New York, NY: Palgrave Macmillan.

Goul Andersen, J. G. (2012). The concept of universalism and its operationalisation in a mixed economy of welfare (Working Paper No. 81). Aalborg: Centre for Com- 
parative Welfare Studies, University of Aalborg.

Hobson, B. (Ed.). (2014). Worklife balance: The agency and capabilities gap. Oxford: Oxford University Press.

Kerr, S. (1982). Deciding about supplementary pensions: A provisional model. Journal of Social Policy, 11(4), 505-517.

Leisering, L. (2009). Germany: A centrist welfare state at the crossroads. In P. Alcock \& G. Craig (Eds.), International social policy: Welfare regimes in the developed world (2nd ed.; pp. 148-170). Basingstoke: Palgrave Macmillan.

Lipsky, M. (1980). Street level bureaucracy: Dilemmas of the individual in public services. New York, NY: Russell Sage.

Merton, R. K. (1968). The Matthew effect in science. Science, 159(3810), 56-63.

OECD. (2003). Transforming disability into ability: Policies to promote work and income security for disabled people. Paris: OECD.

OECD. (2006). Sickness, disability and work: Breaking the barriers. Norway, Poland and Switzerland (Vol. 1). Paris: OECD.

OFAS. (2018). Statistique de l'Al 2018 [Disability insurance statistics 2018]. Bern: OFAS.

Rosenstein, E. (2018). Activer les publics vulnérables? Le cas de l'Assurance-invalidité [Activating vulnerable groups? The case of the Swiss disability insurance].
Geneva: University of Geneva.

Rothstein, B. (1998). Just institutions matter: The moral and political logic of the universal welfare state. Cambridge: Cambridge University Press.

Skocpol, T. (1991). Targeting within universalism: Politically viable policies to combat poverty in the United States. In C. Jencks \& P. E. Peterson (Eds.), The urban underclass (pp. 411-436). Washington, DC: The Brookings Institution.

Swiss Federal Council. (2005). Message concernant la modification de la loi fédérale sur l'assuranceinvalidité (5e révision de l'Al) [Message concerning the amendment of the Federal Law on disability insurance (5th revision)]. Bern: Swiss Federal Council. Retrieved from https://www.admin.ch/opc/fr/federalgazette/2005/4215.pdf

van Kersbergen, K., \& Kraft, J. (2017). De-universalization and selective social investment in Scandinavia? In A. Hemerijck (Ed.), The uses of social investment (pp. 216-226). Oxford: Oxford University Press.

van Oorschot, W. (1991). Non-take up of social security benefits in Europe. Journal of European Social Policy, 1(1), 15-30.

van Oorschot, W. (1995). Realising rights: A multi-level approach to non-take-up of means-tested benefits. Aldershot: Avebury.

\section{About the Authors}

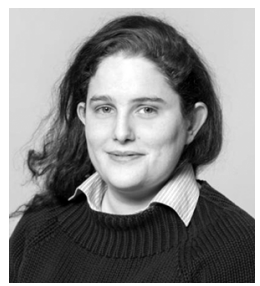

Emilie Rosenstein is Lecturer in Sociology at the University of Geneva. Her main research areas include social policies, especially in the field of disability and youth welfare. Her theoretical background is inspired by the capability approach and the life course perspective. In 2018, she completed a PhD thesis investigating the active turn of the Swiss Disability Insurance and its impact on the life course of its beneficiaries (https://archive-ouverte.unige.ch/unige:102769). She is member of the NCCR "LIVESOvercoming Vulnerability: Life Course Perspectives."

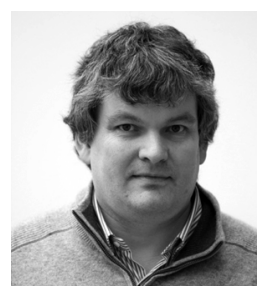

Jean-Michel Bonvin is Professor of Sociology and Social Policy at the University of Geneva. His main fields of expertise include social and labour market policies, organisational innovation in the management of the public sector, and theories of justice, especially the capability approach. His research has been funded, among others, by the European Commission and the Swiss National Science Foundation. He has published extensively in leading international journals such as European Societies, Social Policy and Society or Community, Work \& Family. 